\title{
Correction to: Delirium in Elderly Patients
}

\section{Correction to: A.T. Isik, G.T. Grossberg (eds.), Delirium in Elderly Patients https://doi.org/10.1007/978-3-319-65239-9}

The Appendix "Delirium Assessment Instruments" was missed and it has been included in the backmatter of the book.

The updated online version of this book can be found at https://doi.org/10.1007/978-3-319-65239-9
A. T. Isik (ه)
Department of Geriatric Medicine, Dokuz Eylul University, School of Medicine, Izmir, Turkey
G. T. Grossberg
Department of Neurology and Psychiatry, Saint Louis University, School of Medicine,
St. Louis, MO, USA 